University of Nebraska - Lincoln

DigitalCommons@University of Nebraska - Lincoln

Biological Systems Engineering--Dissertations,

Theses, and Student Research

Biological Systems Engineering

May 1996

\title{
Effect of Screw Configuration and Speed on RTD and Expansion of Rice Extrudate
}

\author{
Siew-Yoong Lee \\ University of Nebraska at Lincoln, siew18@gmail.com \\ Kathryn L. McCarthy \\ University of California-Davis
}

Follow this and additional works at: https://digitalcommons.unl.edu/biosysengdiss

Part of the Biological Engineering Commons

Lee, Siew-Yoong and McCarthy, Kathryn L., "Effect of Screw Configuration and Speed on RTD and Expansion of Rice Extrudate" (1996). Biological Systems Engineering--Dissertations, Theses, and Student Research. 3.

https://digitalcommons.unl.edu/biosysengdiss/3

This Article is brought to you for free and open access by the Biological Systems Engineering at DigitalCommons@University of Nebraska - Lincoln. It has been accepted for inclusion in Biological Systems Engineering--Dissertations, Theses, and Student Research by an authorized administrator of DigitalCommons@University of Nebraska - Lincoln. 
Published in Journal of Food Process Engineering 19:2 (1996), pp. 153-170;

doi 10.1111/j.1745-4530.1996.tb00387.x

Copyright $(1996$ Food \& Nutrition Press, Inc., Trumbull, Connecticut;

published by Blackwell Publishing. Used by permission.

Submitted August 21, 1995; published online January 30, 2007.

\title{
Effect of Screw Configuration and Speed on RTD and Expansion of Rice Extrudate
}

\author{
Siew Yoong Lee ${ }^{1}$ and Kathryn L. McCarthy ${ }^{2}$ \\ ${ }^{1}$ Food Technology Research Center, Malaysian Agricultural Research and Devel- \\ opment Institute, 50774 Kuala Lumpur, Malaysia \\ ${ }^{2}$ Department of Food Science and Technology, \\ University of California-Davis, Davis, CA 95616
}

Corresponding author: K. L. McCarthy, tel 916 752-1487, fax 916 752-4759

\begin{abstract}
The influence of screw configuration and screw speed on the residence time distribution and product expansion was determined for rice meal processed in a corotating twin screw extruder. Screw speed had strong effect on the $E(t)$ - and $\mathrm{F}(\mathrm{t})$-diagrams, with the mean residence time varying inversely with screw speed from $206 \mathrm{~s}$ to $256 \mathrm{~s}$. the F-diagram was modeled by the combination of perfect mixing and plug flow. the P estimates, which express the fraction of material in plug flow, varied inversely with screw speed from 0.41 to 0.55 for the operating conditions in this study. Both screw configuration and screw speed were statistically significant to the expansion ratios of rice extrudate, with the expansion in the height ranging from 2.98 to 4.13 .
\end{abstract}

\section{Introduction}

Extrusion cooking of foods can be described as a process whereby moistened, starchy, and/or proteinaceous foods are cooked and worked into a viscous, plastic-like dough. Cooking is accomplished through the application of heat, either directly by steam injection or indirectly through jackets, and by dissipation of the mechanical energy through shearing of the dough (Harper 1981). 
Although both single screw extruders and twin screw extruders are used in the food and feed industries, there are several advantages of twin screw extruders over single screw extruders. The throughput of the twin screw extruders is independent of feed rate and fluctuations in production rate can be accommodated by the positive displacement action of the screws. They can also provide better mixing and more uniform temperature distribution. Although extrusion of food materials is based on the development of this process in the plastics industry, food materials tend to be more complex due to their biological nature. They consist of carbohydrates, proteins, lipids, salts, water, and vitamins which undergo complex physico-chemical changes when they are subjected to high temperature, pressure and shear in the extruder barrel (Senounci and Smith 1988). These extrusion cooking conditions will ultimately cause some transformation in textural properties as well as some nutritional loss in the extruded products. Therefore, it is important to understand how changes in extrusion operating conditions affect the extrusion process.

Extrusion cooking of food materials containing mainly starch has been widely used for corn and wheat products, while rice extrusion has been studied only in recent years. Similarly, there are fewer extruded rice products on the market than extruded corn or wheat products.

Nevertheless, extruded rice snacks have been gaining popularity in Western markets during recent years (Pan et al. 1992). Rice has the ability to expand well and makes an excellent extruded snack. The bland flavor of rice makes it desirable for preserving more expensive flavor attributes (Huber and Rokey 1990).

The residence time distribution (RTD) in an extruder is a useful means of determining optimal processing conditions for mixing, cooking, and shearing reactions during the process. From the RTD functions one can estimate the degree of mixing, the residence time of mass flow and the average total strain exerted on the mass during its transition and thus provide a clear picture of how an extruder behaves as a chemical reactor (Fichtali and van de Voort 1989). These results coupled with the knowledge of the operating variables such as temperature, screw speed, screw configuration, and moisture content provide necessary information to predict what fraction of the material will undergo specific reactions.

It is possible to analyze and compare the mixing and conveying behavior of different types of twin screw extruders by fitting the RTD data to an appropriate mathematical model. The most widely reported model is based on the combination of perfect mixing and plug flow developed by Wolf and White (1976). In their study using a single screw plasticating extruder, they found that RTD functions of solid conveying process were very close to plug flow $(\mathrm{P}=1)$, and that the mixing conditions, flow patterns, and RTD in a plasticating extruder had significant effects on the 
product. Under their extrusion conditions, screw speed had no significant effect on the RTD.

Wolf et al. (1986) and Lin and Armstrong (1990) studied the RTD in a counterrotating twin screw extruder. Their experimental results showed counterrotating twin screw extruders have unusually near plug flow profiles with $\mathrm{P}=1$ and $\mathrm{P}=0.92$, respectively. Lin and Armstrong (1990) found that changes in screw speed affected the residence time.

Altomare and Ghossi (1986), Kao and Allison (1984), Ollett et al. (1989), Vergnes et al. (1992), Kirby et al. (1988), and Yeh et al. (1991) studied the RTD of corotating twin screw extruders. All of these investigators concluded that screw speed was significant to the RTD, either $\mathrm{E}(\theta)$ or $\mathrm{F}(\theta)$ and/or the mean residence time. Yeh et al. (1991) concluded that increasing screw speed reduced the mean residence time. In these studies, Altomare and Ghossi (1986), Kao and Allison (1984) and Kirby et al. (1988) found that screw configuration had a significant effect on the RTD. However, Ollett et al. (1989) and Vergnes et al. (1992) found that screw configuration did not significantly affect the RTD. Kao and Allison (1984) concluded that the flow characteristics of the more severe screw configuration was closer to the plug flow than the plain screw configuration. Yeh et al. (1991) concluded that decreasing screw speed caused the flow pattern to approach plug flow. Altomare and Ghossi (1986) and Meuser et al. (1987) concluded that flow in the extruder approaches the P estimate of laminar flow in a pipe $(\mathrm{P}=0.5)$.

In starchy extrudates, such as expanded snacks and RTE (ready-toeat) cereals, one of the most important textural properties is the ability of the material to expand at the die. During the expansion stage the extrudate reaches its maximum size as it is formed into the general shape of the product by the die. In order to achieve the desired physical properties of the extrudate, it is necessary to understand how the independent variables and system variables interact with each other. Mercier and Feillet (1975) and Bhattacharya et al. (1986) concluded that the highest expansion ratio was obtained at highest screw speeds in the extrusion cooking of corn grits. Also, Bhattacharya et al. (1986) found that screw geometry, screw speed, and shear within an extruder all affected the expansion of starch. Park (1976) concluded that screw speed had a positive effect on the expansion ratio and total expansion in the extrudates. Vergnes et al. (1987) found that the expansion varied from 1.36 to 5.44 as speed increased.

The objective of this research was to study the effects of screw configuration and screw speed on the residence time distribution and expansion of rice extrudate in a twin screw extruder and slit die. Parameters that characterize the residence time distribution and expansion were evaluated statistically; the F-distribution was characterized by the perfect 
mixing/plug flow model.

\section{Materials and Methods}

Extrusion tests were performed with a System 90 torque rheometer (Haake Buhler, Paramus, NJ) that provided computer control and data acquisition for a MPC/V-30 corotating twin screw extruder (APV, Staffordshire, England), length to diameter ratio (L/D) of 13. The slit die (Haake Buhler, Paramus, NJ) had dimensions of $1.47 \mathrm{~mm} \times 20 \mathrm{~mm} \times 150$ $\mathrm{mm}$. The MPC/V-30 had a clam-shell barrel consisting of three independent temperature zones controlled by electrical heating and compressed air cooling. A computerized data acquisition system was used to record five set temperatures and rotor speed and to acquire four melt temperatures, three pressures at the slit die, and torque data; data acquisition rate was every six seconds. Note that the actual extruder screw speed is 2.5 times the rotor speed due to the torque converter between the torque rheometer and the twin screw extruder. Therefore, rotor speeds of $25,35,45$, 55 , and $65 \mathrm{rpm}$ used in this study correspond to $62.5,87.5,112.5,137.5$, and $162.5 \mathrm{rpm}$, respectively.

Screw configurations incorporated left-handed feed screws with a 30 $\mathrm{mm}$ double lead, mixing paddles, and a 1.0 L/D camelback discharge screw with a $7.5 \mathrm{~mm}$ single lead. The mixing paddles with an L/D of 0.25 were incorporated to increase agitation and retention time.

Rice meal at 25\% wb (Pacific Grain Products, Woodland, CA) was metered at a rate of $30 \mathrm{~g} / \mathrm{min}$ by a K-Tron volumetric feeder (Model T-20, K-Tron Corp., Pitman, NJ). Its fractional wet weight basis moisture content of the rice meal was determined by the AOAC official method 925.09 (AOAC 1990). To prepare the material for extrusion runs, the amount of water to be added to bring the samples to the required moisture content of $25 \%$ wb was added slowly to the samples while being mixed at medium speed in a Hobart mixer (Model N-50, Hobart Corp., Troy, OH).

For each experimental run, $15 \mathrm{~kg}$ of rice meal was prepared. The sample was sealed in polyethylene bags and stored in the cold room at $5{ }^{\circ} \mathrm{C}$ for a minimum of $24 \mathrm{~h}$ but not more than $72 \mathrm{~h}$ for moisture equilibration. The feed material was then allowed to equilibrate to room temperature prior to extrusion. This preconditioning procedure was employed to ensure uniform mixing and hydration and to minimize variability in the state of the feed material.

The set temperatures for the extruder and die were the same for each extruder run. The set temperatures for the extruder barrel were $30^{\circ} \mathrm{C}$ at the first section, $60^{\circ} \mathrm{C}$ at the second section, $100{ }^{\circ} \mathrm{C}$ at the third section, $130{ }^{\circ} \mathrm{C}$ at the adapter piece into the die and $130^{\circ} \mathrm{C}$ at the die. During the experimental runs, melt temperatures were recorded at $40 \pm 5,60 \pm 5,85 \pm$ $10^{\circ} \mathrm{C}$ for the barrel sections and $135 \pm 2{ }^{\circ} \mathrm{C}$ at the die section. 


\section{Experiment Design}

The experimental design was carried out as a split plot design (Table 1). Three screw configurations were chosen to achieve a range of die pressures from $3000 \mathrm{kPa}$ to $4200 \mathrm{kPa}$; they were designated Low, Medium, and Severe (Figure 1). The Low screw configuration had six pieces of $1.5 \mathrm{~L} / \mathrm{D}$ feed screws, followed by three $1.0 \mathrm{~L} / \mathrm{D}$ feed screws and 1.0 $\mathrm{L} / \mathrm{D}$ discharge screw downstream. The Medium screw configuration had six pieces of $1.5 \mathrm{~L} / \mathrm{D}$ feed screws, three mixing paddles oriented at $30^{\circ}$, $60^{\circ}$, and $90^{\circ}$ feed forward, one $1.0 \mathrm{~L} / \mathrm{D}$ feed screw, followed by one mixing paddle oriented at $90^{\circ}$ feed forward, and 1.0 L/D discharge screw downstream. The Severe screw configuration had six pieces of $1.5 \mathrm{~L} / \mathrm{D}$ feed screws, two 1.0 L/D feed screws, and four mixing paddles oriented at $30^{\circ}, 60^{\circ}, 90^{\circ}$, and $30^{\circ}$ feed forward and $1.0 \mathrm{~L} / \mathrm{D}$ discharge screw.

Within the three replicates, the three screw configurations were randomly assigned. For each screw configuration, the rotor speeds of 25, 35, 45,55 , and $65 \mathrm{rpm}$ were then randomly assigned. This grouping of five rotor speeds is referred to as an "experiment" because all the data was collected on the same day, hence the split plot design. Barrel temperatures toward the end of the day were systematically higher; however due to the randomization procedure, each rotor speed was affected equally.

\section{Residence Time Distribution}

Based on a calibration curve for rice meal extrudate, $0.025 \mathrm{~g}$ of red dye sodium erythrosine (Sigma Chemical Co., St. Louis, MO) was mixed with $1.0 .0 \mathrm{~g}$ of rice meal and the amount of water needed to bring the moisture content of the tracer to that of the feed material $(25 \% \mathrm{wb})$. These tracer

Table 1. Experimental Design

\begin{tabular}{|c|c|c|c|c|c|c|c|c|}
\hline & plicat & & & eplicate & & & plicate & \\
\hline EXP & EXP & EXP 3 & EXP 4 & EXP 5 & EXP 6 & EXP 7 & EXP 8 & EXP 9 \\
\hline $\mathrm{L}$ & S & M & $\mathrm{M}$ & L & S & M & S & L \\
\hline 55 & 55 & 25 & 55 & 35 & 35 & 35 & 45 & 25 \\
\hline 65 & 65 & 65 & 45 & 55 & 45 & 65 & 65 & 55 \\
\hline 45 & 35 & 35 & 35 & 25 & 55 & 45 & 25 & 65 \\
\hline 25 & 25 & 45 & 25 & 65 & 25 & 25 & 55 & 35 \\
\hline 35 & 45 & 55 & 65 & 45 & 65 & 55 & 35 & 45 \\
\hline
\end{tabular}

Screw Configuration: L=Low; $M=$ Medium; $S=$ Severe

Rotor speed $=25,35,45,55,65 \mathrm{rpm}$

Screw speed $=$ Rotor speed $\times 2.5$ 
Low Screw Configuration

\begin{tabular}{|c|c|c|c|c|c|c|c|c|c|}
\hline $\mathrm{F}$ & $\mathrm{F}$ & $\mathrm{F}$ & $\mathrm{F}$ & $\mathrm{F}$ & $\mathrm{F}$ & $\mathrm{F}$ & $\mathrm{F}$ & $\mathrm{F}$ & $\mathrm{D}$ \\
\hline
\end{tabular}

Medium Screw Configuration

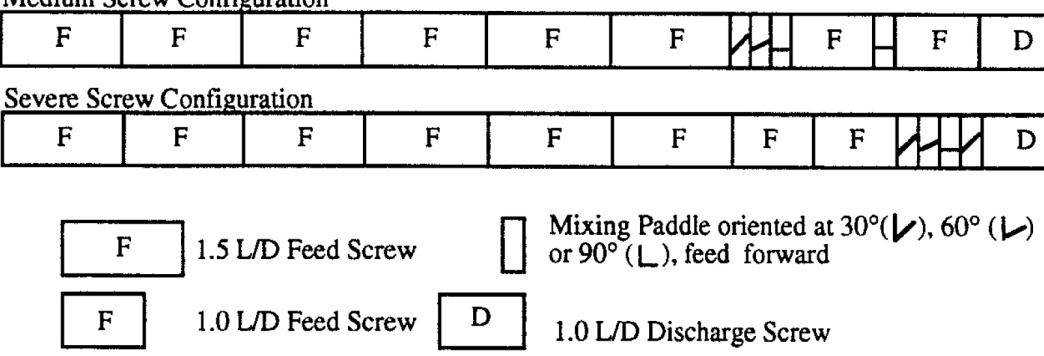

Figure 1. Diagram of Screw Configurations

samples were sealed in polyethylene cups and stored in the cold room at $5{ }^{\circ} \mathrm{C}$ for a minimum of $24 \mathrm{~h}$ but not more than $72 \mathrm{~h}$ to equilibrate. The tracer samples were then allowed to equilibrate to room temperature prior to extrusion. Once steady state conditions were achieved on the extruder as indicated by constant temperature, pressure and torque measurements, a strip of the extrudate was cut as a control for color intensity. The tracer sample was added as a pulse input through the inlet port of the extruder. At the same instant, a timer was started and a length of extrudate was cut at an interval of $20 \mathrm{~s}$ for a duration of $15 \mathrm{~min}$. All samples for the first five min and then every third sample for the next $10 \mathrm{~min}$ were selected for color measurement.

All the samples, including the control, were dried overnight in a force air oven at $60^{\circ} \mathrm{C}$ to equilibrate the moisture. The dried samples were ground in a IKA-analytical mill A10 (Type A10S2, Staufen, Germany). The ground material was then sieved through a 50 US standard sieve (Newark Wire Cloth Co., Newark, NJ). The uniform powder was analyzed for color on a Spectrophotometer CM-2002 (Minolta Cop., Ramsey, $\mathrm{NJ})$. Measurements were calculated based on the $2^{\circ}$ Standard Observer D65 illuminant. Measurement results were then displayed in $\mathrm{L}^{*}, \mathrm{a}^{*}, \mathrm{~b}^{*}$ values which were registered and stored in the memory card. The $\mathrm{L}^{*}$ value refers to lightness, $a^{*}$ refers to redness-greenness, and $b^{*}$ refers to yellowness-blueness (Hunter 1975). Each measurement was averaged from three readings. These values were then used in the calculations of the RTD functions. The values of $a^{*}$ and $b^{*}$ were subtracted from the standard values of the control. The red color intensity was calculated as the "Index of Saturation" (Francis and Clydesdale 1975) as follows:

$$
c=\left[(\Delta \mathrm{a})^{2}+(\Delta \mathrm{b})^{2}\right]^{1 / 2}
$$

where, $\Delta a=a^{*}$ standard $-a^{*} ; \Delta b=b^{*}$ standard $-b^{*}$. 


\section{RTD Functions}

RTD can generally be described with two functions which are closely related: the $E(t)$ - and $F(t)$-diagrams (Levenspiel 1972). The response of the extruder to a pulse at the inlet is given by an $\mathrm{E}(\mathrm{t})$ diagram, which represents the age distribution of the material in the extruder.

$$
\mathrm{E}(\mathrm{t})=\frac{\mathrm{c}}{\int_{0}^{\infty} \mathrm{cdt}} \approx \frac{\mathrm{c}_{\mathrm{i}}}{\sum_{\mathrm{i}=0}^{\infty} \mathrm{c}_{\mathrm{i}} \Delta \mathrm{t}}
$$

where $\mathrm{c}$ is the tracer concentration at time $\mathrm{t}$.

The $F(t)$-diagram is related to the $E(t)$-diagram and it represents the cumulative distribution function in the exit stream at any time. It is given by

$$
F(t)=\int_{0}^{t} E(t) d t \cong \frac{\sum_{i=0}^{i=t} c_{i} \Delta t}{\sum_{i=0}^{i=\infty} c_{i} \Delta t}
$$

The mean residence time $(\overline{\mathrm{t}})$, which represents the mean time the material spent in the extruder, is given by

$$
\bar{t}=\int_{0}^{t} t E(t) d t \cong \frac{\sum_{i=0}^{\infty} t_{i} c_{i} \Delta t}{\sum_{i=0}^{\infty} c_{i} \Delta t}
$$

Since it is common to plot residence time distributions in a normalized form, the normalized time, E-diagram and F-diagram are

$$
\begin{aligned}
& \theta=\mathrm{t} / \mathrm{t} \\
& \mathrm{E}(\theta)=\overline{\mathrm{t}} \mathrm{E}(\mathrm{t}) \\
& \mathrm{F}(\theta)=\mathrm{F}(\mathrm{t})
\end{aligned}
$$

respectively. For this study, the dependent variables that characterized the residence time and residence time distribution were $\mathrm{E}(\theta)$ maximum, $\theta$ at $\mathrm{E}(\theta)$ maximum, mean residence time, $\overline{\mathrm{t}}$, and $\mathrm{F}(\theta)$ at $\theta=1$. In addition, the $P$ estimate, which characterizes the fraction of material in plug flow, was evaluated from the $F(\theta)$-diagram.

\section{Expansion Ratios of Extrudate}

Two expansion ratios characterized the rice meal extrudate. The expansion ratio in the width direction $\left(\mathrm{E}_{\mathrm{w}}\right)$ is expressed as the ratio of the 
measurement of the width of the extrudate to the width of the slit die (Bhattacharya et al. 1986). The expansion ratio in the height direction $\left(\mathrm{E}_{\mathrm{h}}\right)$ is expressed as the ratio of the measurement of the height of the extrudate to the height of the slit die.

When steady state extrusion conditions were achieved, a $50 \mathrm{~cm}$ continuous length of extrudate was cut for the evaluation of expansion ratios of the extrudate. From this length, 10 pieces of $5 \mathrm{~cm}$ length were further cut. These samples were dried overnight in a forced air oven at $60^{\circ} \mathrm{C}$ to equilibrate moisture. These samples were removed from the oven and stored in the dessicator for further analysis. Samples were randomly chosen for the determination of expansion ratios. The reported results were the average of ten measurements. Based on thermal curves using Differential Scanning Calorimetry, the starch in these extrudate samples was $100 \%$ gelatinized under all experimental conditions (Lee 1994).

\section{Results and Discussion}

The dependent variables in this study were $\mathrm{E}(\theta)$ maximum, $\theta$ at $\mathrm{E}(\theta)$ maximum, mean residence time, $\bar{t}, F(\theta)$ at $\theta=1$, the $P$ estimate, and expansion ratios. A split plot design using SuperANOVA (Abacus Concepts, Inc., Berkeley, CA) was used for statistical analysis. For each of the variables, the statistical analysis included the variance table, means table, Duncan New Multiple Range for the significant variables, plots of predicted and experimental values as well as scattergram of residuals.

\section{RTD Functions}

The RTD dependence on screw speed is shown in Figure 2-4. As illustrated, as the screw speed increased the peak of the $\mathrm{E}(8)$ diagram decreased. The $\mathrm{E}(\theta)$ diagrams were characterized by their peaks of $\mathrm{E}(\theta)$ values and also the normalized time when the peak occurred. Screw speed was highly significant with regards to the peak of $\mathrm{E}(\theta)$ diagram with a statistical $p$-value of 0.0002 . The means of $E(\theta)$ maximum indicated that as the rotor speed (screw speed $=2.5 \times$ rotor speed) increased from 25 rpm to $65 \mathrm{rpm}, \mathrm{E}(\theta)$ maximum decreased from 0.907 to 0.766 . Refer to Table 2 for the summary of RTD functions. The Duncan New Multiple Range of the effect of speed on the $\mathrm{E}(\theta)$ maximum indicated that 65,55 , 45 , and $35 \mathrm{rpm}$ were significantly different from $25 \mathrm{rpm}$ and that only 25 and $65 \mathrm{rpm}$ were significantly different from $35 \mathrm{rpm}$. In addition, the scattergram of residuals of $\mathrm{E}(\theta)$ maximum showed that all the residuals are randomly distributed within the region of less than three standard deviations which indicated that the assumptions of normality and constancy of variance were valid. 


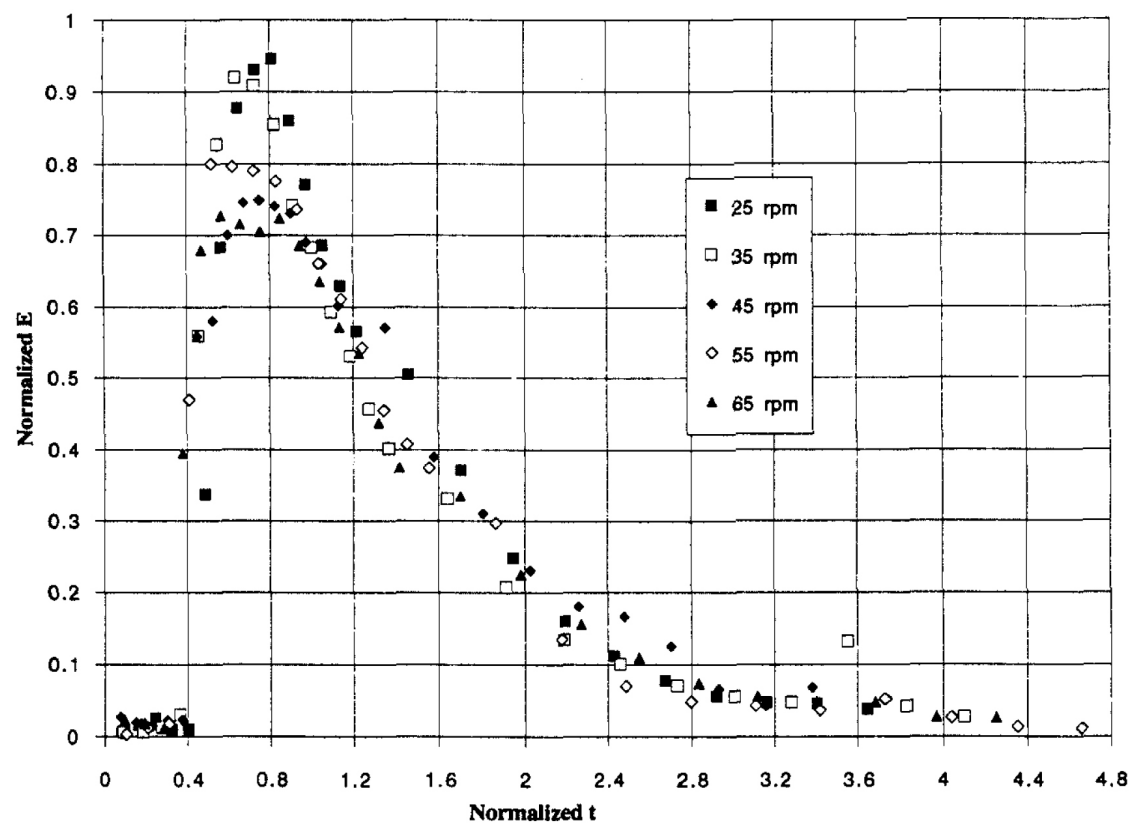

Figure 2. E-Diagram For Low Screw Configuration

As mentioned above, the time, $\theta$, when the peak of $\mathrm{E}(\theta)$ value occurred characterized the $\mathrm{E}(\theta)$ diagram. Screw speed was highly significant to the time, $\theta$ at $\mathrm{E}(\theta)$ maximum with a p-value of 0.0021 . Screw speed was inversely proportional to the time, $\theta$ at $\mathrm{E}(\theta)$ maximum. Table 2 shows that as rotor speed increases from 25 to $65 \mathrm{rpm}, \theta$ decreases from 0.754 to 0.641. The Duncan New Multiple Range of the effect of speed on $\theta$ at $E(\theta)$ maximum indicated that 65,55 , and $45 \mathrm{rpm}$ were significantly different from $25 \mathrm{rpm}$ but not $35 \mathrm{rpm}$. The scattergram of residuals of $\theta$ at $\mathrm{E}(\theta)$ maximum indicated that all the residuals were within \pm 0.125 which was \pm two standard deviations. As with $\mathrm{E}(\theta)$ maximum, the assumptions of normality and constancy of variance were valid for $\theta$ at $\mathrm{E}(\theta)$ maximum.

Screw speed had a high significance with a p-value of 0.0001 on the mean residence time, $\overline{\mathrm{t}}$ (Table 2). Similar results were obtained by Kao and Allison (1984), Altomare and Ghossi (1986), and Yeh et al. (1991). The Duncan New Multiple Range of the effect of speed on mean time showed that rotor speed of 65 and $55 \mathrm{rpm}$ were significantly different from 45, 35 , and $25 \mathrm{rpm}$. Scattergram of residuals indicated that all residuals were randomly distributed within less than \pm three standard deviations. The assumptions of normality and constancy of variance were valid. 


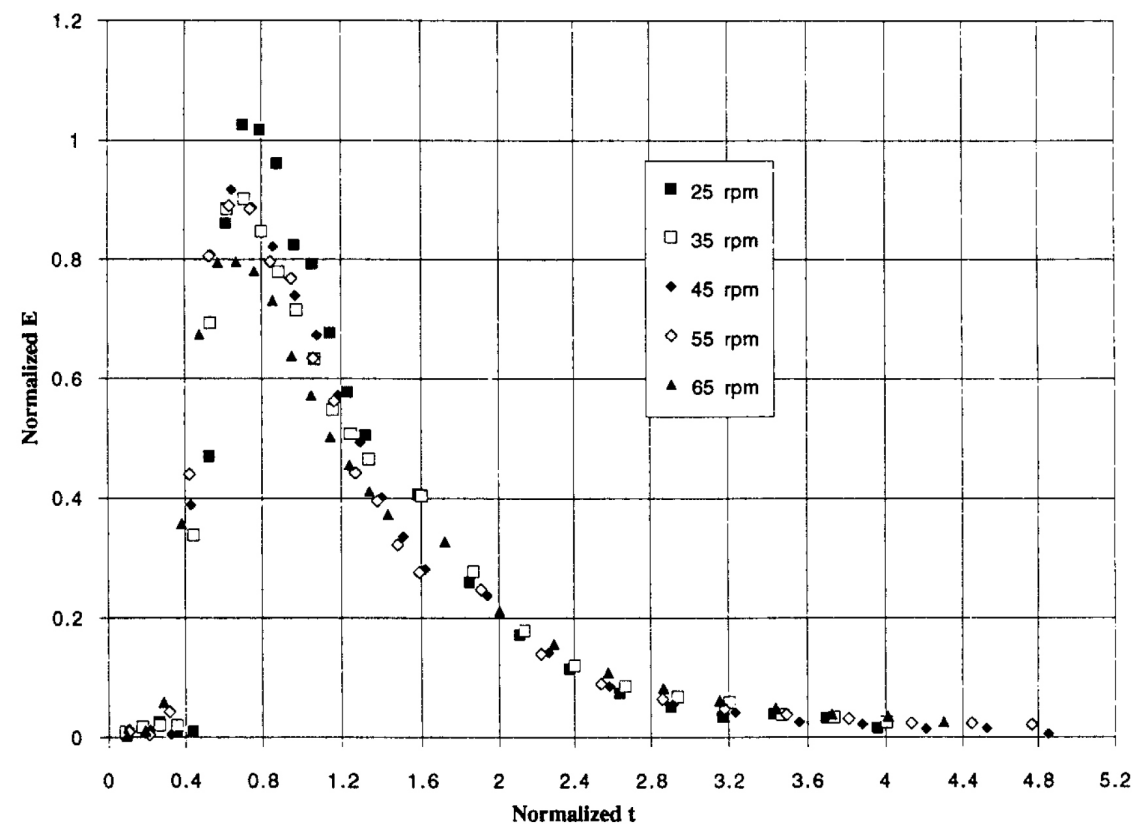

Figure 3. E-Diagram For Medium Screw Configuration

The $F(\theta)$-diagrams as shown in Figure 5-7 superimpose data from all screw speeds for each of the three screw configurations. As indicated in each of the figures, the overall mixing pattern and shape of $F(\theta)$ did not change. The F-diagram is characterized by the value of $F(\theta)$ at $\theta=1$. Statistically, it was found that screw speed had a significant effect on the $F(\theta)$ at $\theta=1$ (Table 2). The Duncan New Multiple Range of the effect of speed on $F(\theta)$ at $\theta=1$ indicated that rotor speed of 65 and $55 \mathrm{rpm}$ were significantly different from 45 and $25 \mathrm{rpm}$, and only $55 \mathrm{rpm}$ was significantly different from $35 \mathrm{rpm}$. Scattergram of residuals showed that all the residuals were within \pm 0.03 which was about \pm two standard deviations. The assumptions of normality and constancy of variance were valid.

\section{RTD Flow Models}

The experimental $F(\theta)$-diagrams were characterized using the Wolf and White model (1976); flow is modeled by considering extrusion as a combination of perfect mixing and plug flow. This model is expressed as

$$
\begin{array}{lr}
F(\theta)=1-\mathrm{e}^{[-(1 /(1-\mathrm{P})(\theta-\mathrm{P})]} & \text { for } \theta \geq P \\
\mathrm{~F}(\theta)=0 & \text { for } 0<\theta<P
\end{array}
$$




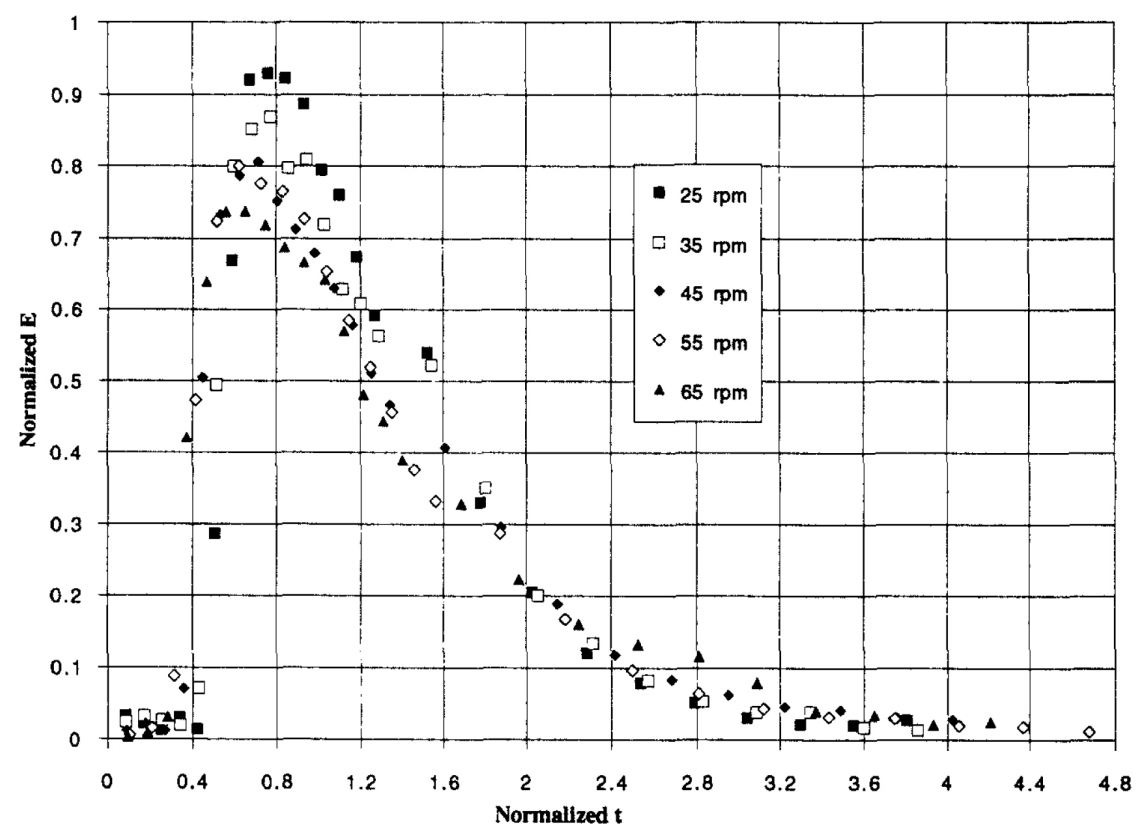

Figure 4. E-Diagram for Severe Screw Configuration

Table 2. Summary Table of RTD Functions

\begin{tabular}{ccccc}
\hline $\begin{array}{c}\text { Rotor } \\
\text { Speed (rpm) }\end{array}$ & $\mathrm{E}(\theta) \mathrm{max}^{*}$ & $\theta$ at $\mathrm{E}(\theta) \mathrm{max}^{*}$ & $\mathrm{~F}(\theta)$ at $\theta=1^{*}$ & $\overline{\mathrm{t}}(\mathrm{sec})^{*}$ \\
\hline 25 & $0.907 \pm 0.028$ & $0.754 \pm 0.022$ & $0.438 \pm 0.005$ & $256 \pm 10$ \\
35 & $0.838 \pm 0.036$ & $0.712 \pm 0.017$ & $0.452 \pm 0.008$ & $236 \pm 9$ \\
45 & $0.789 \pm 0.020$ & $0.668 \pm 0.019$ & $0.447 \pm 0.006$ & $240 \pm 11$ \\
55 & $0.790 \pm 0.016$ & $0.635 \pm 0.028$ & $0.472 \pm 0.004$ & $199 \pm 4$ \\
65 & $0.766 \pm 0.021$ & $0.641 \pm 0.018$ & $0.465 \pm 0.005$ & $206 \pm 6$ \\
\hline
\end{tabular}

${ }^{*}$ Mean \pm Standard Error of nine readings

Screw Speed $=$ Rotor Speed $\times 2.5$ 


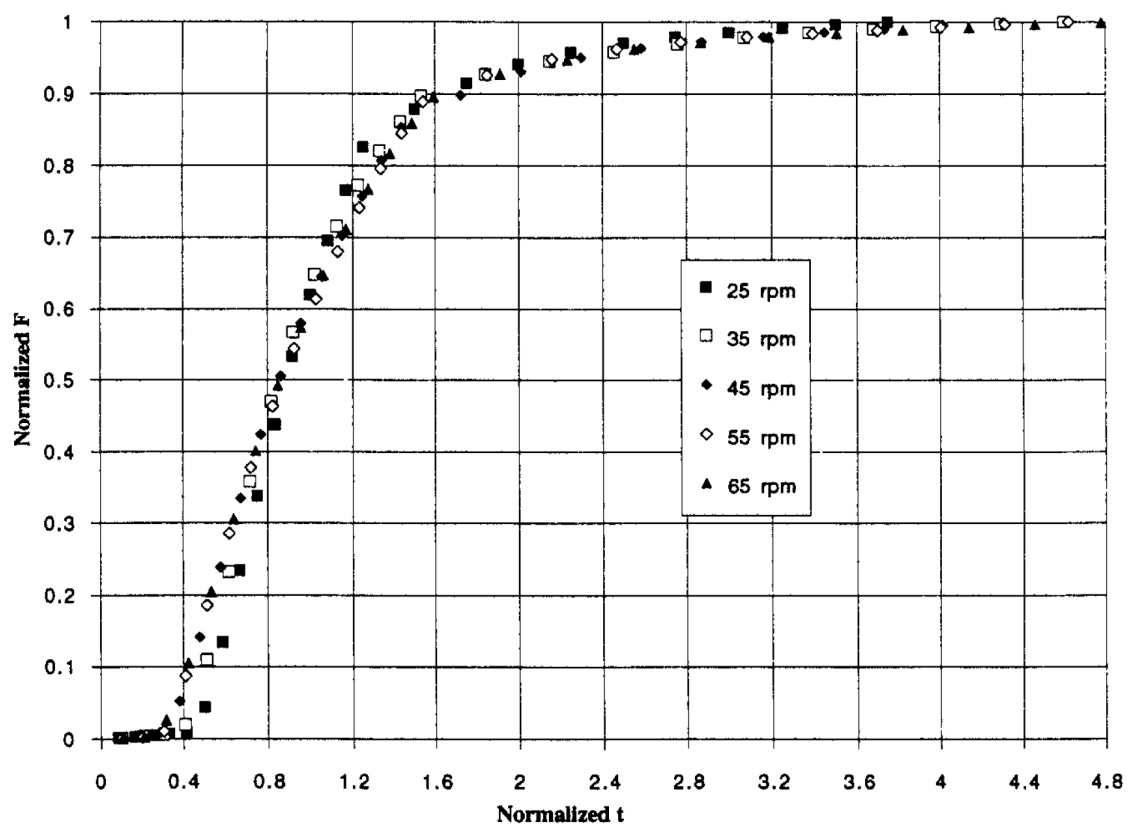

Figure 5. F-Diagram for Low Screw Configuration

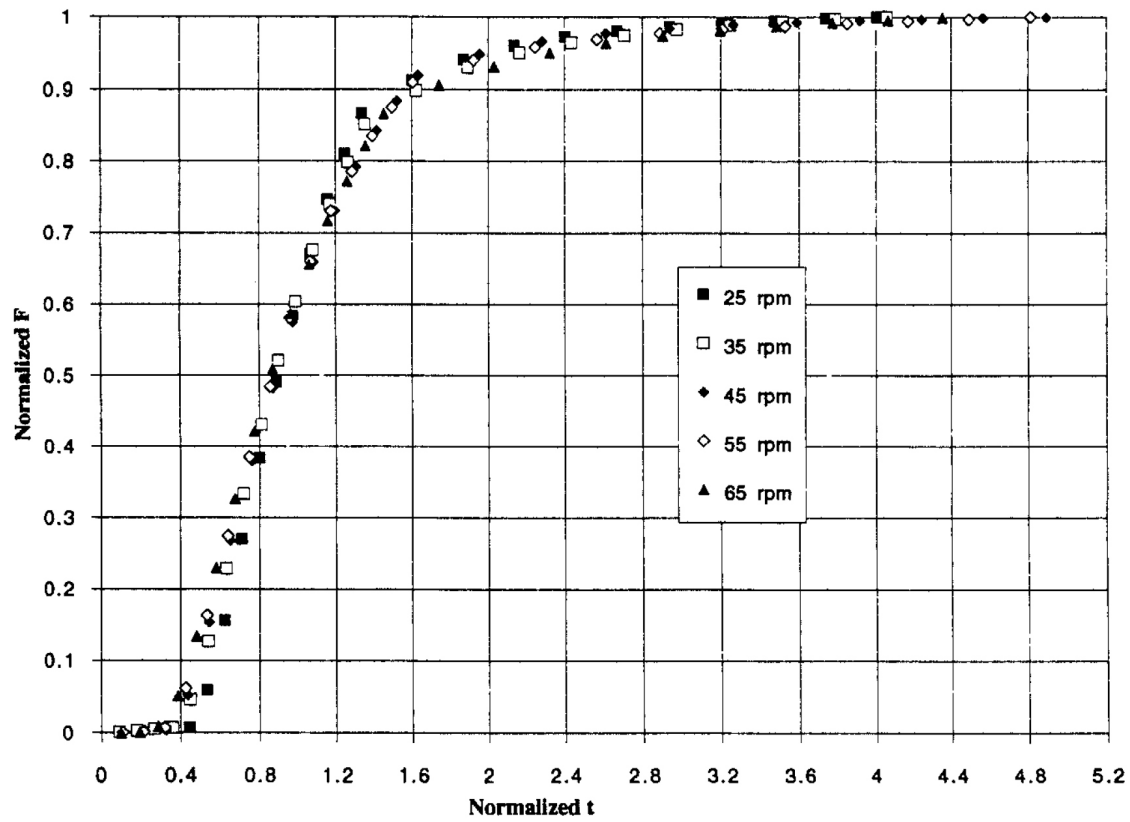

Figure 6. F-Diagram for Medium Screw Configuration 


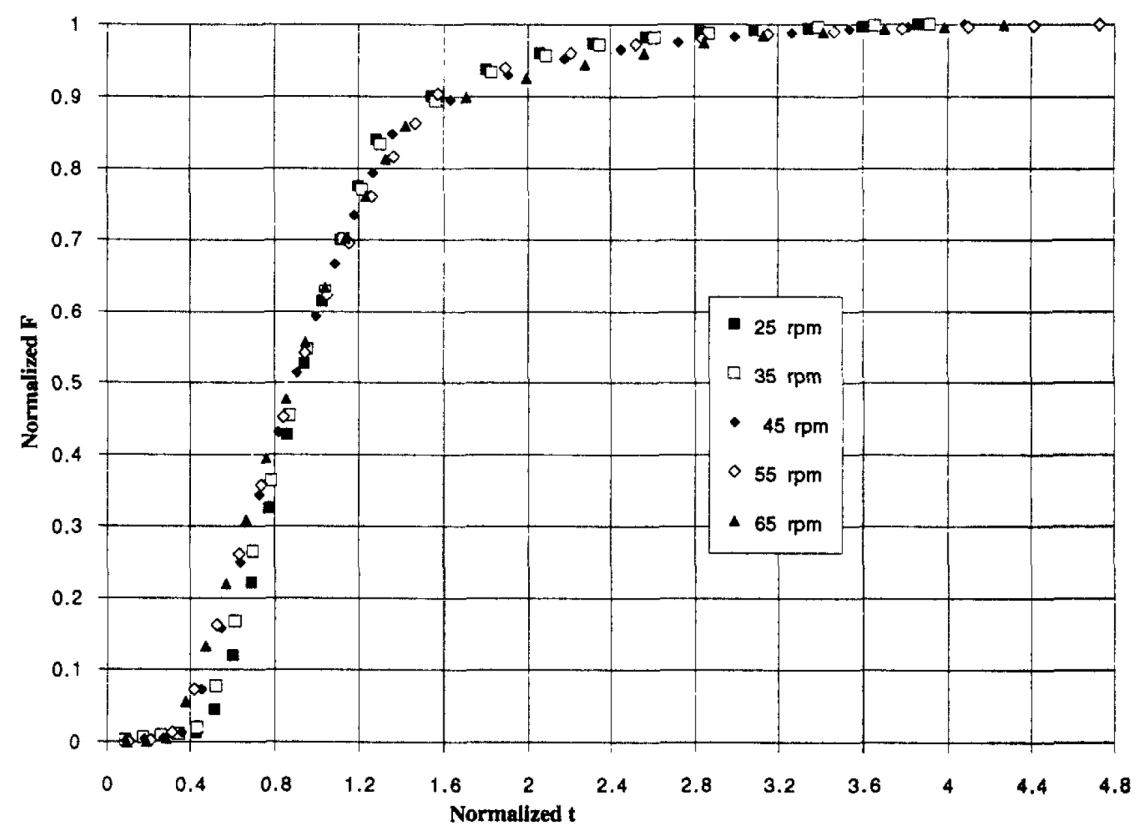

Figure 7. F-Diagram for Severe Screw Configuration

where $\mathrm{P}$ is the fraction of material in plug flow. AR-Derivative-free nonlinear regression (BMDP Statistical Software, Inc., Los Angeles, CA) was used to analyze the $\mathrm{P}$ estimate for each F-diagram. Screw speed was highly significant to the $\mathrm{P}$ estimate with a p-value of 0.0001 . Table 3 shows the inverse relationship of speed and the P estimate. As rotor speed increased from 25 to $65 \mathrm{rpm}$, the P estimate decreased from 0.551 to 0.406 . A P estimate of 0.48 was found to give a reasonable fit to all experimental data obtained in this study. This value indicated that the flow in the extruder approached the $\mathrm{P}$ estimate of laminar flow in a pipe $(\mathrm{P}=$ $0.5)$ under these experimental conditions. Similar results were obtained by Altomare and Ghossi (1986) and Meuser et al. (1987). For comparative purposes, the curves for perfect mixing, plug flow, laminar flow in a pipe, and a representative curve from this study are shown in Figure 8, as well as the curve for the fitted $\mathrm{F}(\mathrm{P}=0.48)$.

The Duncan New Multiple Range of the effect of speed on the P estimate of RTD flow models showed that all speeds were significantly different from each other, except $65 \mathrm{rpm}$ was not significantly different from $55 \mathrm{rpm}$; and $45 \mathrm{rpm}$ was not significantly different from $35 \mathrm{rpm}$. The scattergram of residuals of the $\mathrm{P}$ estimate showed that all the residuals were within \pm 0.05 which was less than \pm two standard deviations. 
Table 3. P Estimate for the RTD Flow Models

\begin{tabular}{ccc}
\hline Rotor Speed $(\mathrm{rpm})$ & P estimate* $^{*}$ & Std. Deviation \\
\hline 25 & $0.551 \pm 0.006$ & 0.018 \\
35 & $0.486 \pm 0.013$ & 0.040 \\
45 & $0.479 \pm 0.011$ & 0.034 \\
55 & $0.419 \pm 0.011$ & 0.032 \\
65 & $0.406 \pm 0.009$ & 0.026 \\
\hline
\end{tabular}

* Mean \pm Standard Error of nine readings

Screw Speed $=$ Rotor Speed $\times 2.5$

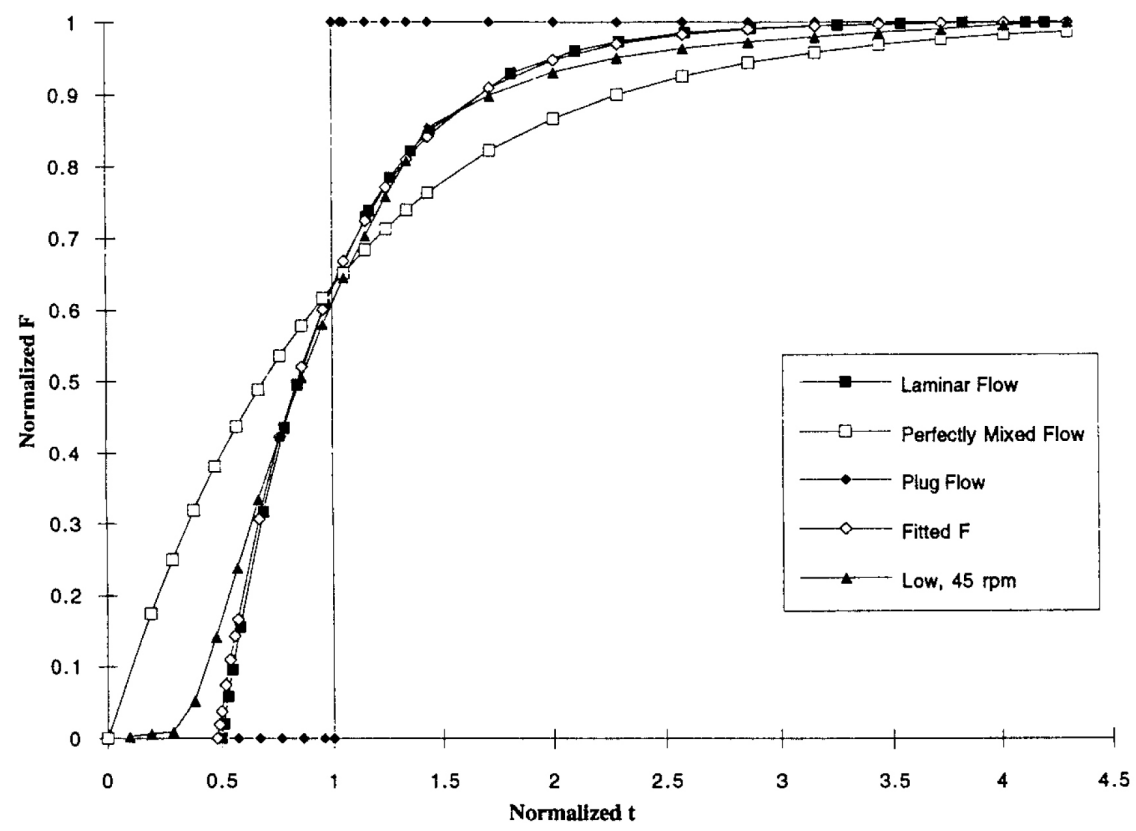

Figure 8. Comparison of F-diagrams for: laminar flow, perfectly mixed flow, plug flow, a representative experimental curve, and the $\mathrm{P}=0.48$ curve that represents the fit for all experimental data in this study. 


\section{Expansion Ratios}

Unlike the residence time variables, the expansion ratios were functions of screw configuration, as well as screw speed. The screw configuration and speed were highly significant to the expansion ratio in the width dimension $\left(E_{w}\right)$; the p-value was 0.0001 for each. As the severity of the screw configuration increased, $\mathrm{E}_{\mathrm{w}}$ increased from 1.029 to 1.094 with each screw configuration significantly different from the others (Table 4). With respect to screw speed, $\mathrm{E}_{\mathrm{w}}$ increased from 1.022 to 1.087 as the screw speed increased (Table 5). All speeds were significantly different from each other except for $35 \mathrm{rpm}$, which was not significantly different from $45 \mathrm{rpm}$. The scattergram of residuals of expansion ratio $\left(\mathrm{E}_{\mathrm{w}}\right)$ showed that all the residuals were within \pm 0.025 which was less than \pm two standard deviations.

Table 4. Effect of Screw Configuration on Expansion Ratios

\begin{tabular}{ccc}
\hline $\begin{array}{c}\text { Screw } \\
\text { Configuration }\end{array}$ & Expansion $\left(\mathrm{E}_{\mathrm{w}}\right)^{*}$ & Expansion $\left(\mathrm{E}_{\mathrm{h}}\right)^{*}$ \\
\hline Low & $1.029 \pm 0.004$ & $3.189 \pm 0.083$ \\
Medium & $1.049 \pm 0.006$ & $3.464 \pm 0.128$ \\
Severe & $1.094 \pm 0.011$ & $4.038 \pm 0.143$ \\
\hline
\end{tabular}

*Mean \pm Standard Error of 15 readings

Table 5. Effect of Screw Speed on Expansion Ratios

\begin{tabular}{ccc}
\hline Rotor Speed $(\mathrm{rpm})$ & Expansion $\left(\mathrm{E}_{\mathrm{w}}\right)^{*}$ & Expansion $\left(\mathrm{E}_{\mathrm{h}}\right)^{*}$ \\
\hline 25 & $1.022 \pm 0.005$ & $2.978 \pm 0.095$ \\
35 & $1.046 \pm 0.010$ & $3.311 \pm 0.127$ \\
45 & $1.054 \pm 0.008$ & $3.573 \pm 0.149$ \\
55 & $1.076 \pm 0.013$ & $3.824 \pm 0.162$ \\
65 & $1.087+0.016$ & $4.132 \pm 0.177$ \\
\hline
\end{tabular}

* Mean \pm Standard Error of nine readings

Screw Speed $=$ Rotor Speed $\times 2.5$ 
Likewise, the screw configuration and screw speed were significant to the expansion ratio in the height direction, $\left(\mathrm{E}_{\mathrm{h}}\right)$, with p-values of 0.0025 and 0.0001 , respectively. The value of $E_{h}$ increased with the severity of screw configuration, i.e., from 3.189 for the Low screw configuration to 4.038 for the Severe screw configuration (Table 4). The screw configurations were significantly different, with the exception of the Low and Medium screw configurations. In other words, the Low and Severe configurations were statistically different, as were the Medium and Severe configurations. Table 5 illustrates the relationship between the screw speed and $E_{h}$, with all screw speeds significantly different from each other. The scattergram of residuals of expansion ratio $\left(E_{h}\right)$ showed that all the residuals were within \pm 0.316 which was less than \pm two standard deviations.

\section{Conclusions}

The experimental studies reported here using the dye technique enabled us to study the effects of screw configuration and speed on the residence time distribution. In addition, expansion ratios were evaluated as functions of screw configuration and screw speed. The following significant findings in this study were:

(1) Screw speed was highly significant to the residence time variables: $\mathrm{E}(\theta)$ maximum, time at $\mathrm{E}(\theta)$ maximum, mean residence time, and $\mathrm{F}(\theta)$ at $\theta=1$. As screw speed increased, $\mathrm{E}(\theta)$ maximum decreased, time at $\mathrm{E}(\theta)$ maximum decreased, mean residence time decreased, and $\mathrm{F}(\theta)$ at $\theta=1$ increased.

(2) With respect to modeling the $F(\theta)$-diagram, the $\mathrm{P}$ estimate ranged from 0.406 at $65 \mathrm{rpm}$ rotor speed to 0.551 at $25 \mathrm{rpm}$. The P estimate of 0.48 represented all experimental data, which is close to the P estimate of 0.5 for laminar flow in a pipe.

(3) The expansion ratios were strong functions of screw configuration and screw speed, both in the width and height directions. These properties were much more sensitive to changes in screw configuration than the residence time variables.

\section{Acknowledgments}

This research was funded by NSF Grant BES-9057676. 


\section{References}

Altomare, R. E., and Ghossi, P. 1986. An analysis of RTD patterns in a twin screw cooking extruder. Biotechnol. Prog. 2, 157-163.

AOAC 1990. Official Methods of Analysis of the Association of Officia1 Analytical Chemists, $15 \mathrm{Ed}$. Arlington, VA.

AR-Derivative-free Nonlinear Regression. 1990. BMDP Statistical Software, Inc., Los Angeles, CA.

Bhattacharya, M., Hanna, M. A., and Kaufman, R. E. 1986. Textural properties of extruded plant protein blends. J. Food Sci. 51(4),

Bruin, S., Van Zuilichem, D. J., and Stolp, W. 1978. A review of fundamental and engineering aspects of extrusion of biopolymers in a single screw extruder. $J$. Food Process Engineering 2, 1-37.

Fichtali, J., and van de Voort, F. R. 1989. Fundamental and practical aspects of twin screw extrusion. Cereal Foods World 34(11), 921-929.

Francis, F. J., and Clydesdale, F. M. 1975. Food Colorimetry: Theory and Applications, Van Nostrand Reinhold/AVI, New York.

Harper, J. M. 1981. Extrusion of Food, Vol. I. , CRC Press, Boca Raton, FL.

Huber, G. R., and Rokey, G. J. 1990. Extruded snacks. In Snack Food, (R. G. Booth, ed.) Van Nostrand Reinhold, New York.

Hunter, R. S. 1975. The Measurement of Appearance. John Wiley \& Sons, Canada.

Kao, S. V., and Allison, G. R. 1984. Residence time distribution in a twin screw extruder. Polymer Eng. Sci. 24, 645-651.

Kirby, A. R., Ollett, A. L., Parker, R., and Smith, A. C. 1988. An experimental study of screw configuration effects in a twin screw extrusion cooking of maize grits. J. Food Eng. 8, 247-272.

Lee, S. Y. 1994. Effect of screw configuration and speed on the extrusion of rice meal. M. Sc. thesis, University of California, Davis, CA.

Levenspiel, O. 1972. Chemical Reaction Engineering, 2nd Ed., Wiley, New York.

Lin, J. K., and Armstrong, D. J. 1990. Process variables affecting residence time distributions of cereals in an intermeshing, counter rotating twin screw extruder. Trans. ASAE 33(6), 1971-1978.

Mercier, C., and Feillet, P. 1975. Modification of carbohydrate components by extrusion-cooking of cereal products. Cereal Chem. 52(3), 283-297.

Meuser, F., Pfaller, W., and van Lengerich, B. 1987. Technological aspects regarding specific changes to the characteristic properties of extrudates by HTST-extrusion cooking. In Extrusion Technology For The Food Industry, (C. O'Connor, ed.) Elsevier Applied Science, London. 988-993. 
Ollett, A. L., Li, Y., Parker, R., and Smith, A. C. 1989. A comparative study of the conveying performance of screws in a twin screw corotating extrusion-cooker. J. Food Eng. 10, 165-181.

Pan, B. S., Kong, M. S., and Chen, H. H. 1992. Twin screw extrusion for expanded rice products: Processing parameters and formulation of extrudate properties. In Food Extrusion Science and Technology, (J. L. Kokini, C. T. Ho, and M. W. Kame, eds.) Marcel Dekker, New York.

Park, K. H. 1976. Elucidation of the extrusion puffing process. Ph.D. thesis, University of Illinois, Urbana, IL.

Senounci, A., and Smith, A. C. 1988. An experimental study of food melt rheology. I. Shear viscosity using a slit die viscometer and a capillary rheometer. Rheol. Acta. 27, 546-554.

SuperANOVA. 1991. Accessible General Linear Modeling. Abacus Concepts, Berkeley, CA.

Vergnes, B., Barres, C., and Tayeb, J. 1992. Computation of residence time and energy distributions in the reverse screw element of a twin screw extrusion cooker. J. Food Eng. 16, 215-237.

Vergnes, B., Villemaire, J. P., Colonna, P., and Tayeb, J. 1987. Interrelationships between thermomechanical treatment and macromolecular degradation of maize starch in a novel rheometer with preshearing. J. Cereal Sci. 5, 189-202.

Wolf, D., Holin, N., and White, D. H. 1986. Residence time distribution in a commercial twin screw extruder. Polymer Eng. and Sci. 26, 640-646.

Wolf, D., and White, D. H. 1976. Experimental study of the RTD in plasticating screw extruders. AIChEJ 22, 122-131.

Yeh, A. I., Hwang, S. J., and Guo, J. J. 1991. Effects of screw speed and feed rate on residence time distribution and axial mixing of wheat flour in twin screw extruder. J. Food Eng. 17, 1-13. 